\title{
Charlotte Schmid, Le Don de voir. Premières représentations krishnaiites de la région de Mathurā
}

Paris, Publications de l'École Française d'Extrême-Orient, 2010, 749 p.

Édith Parlier-Renault

\section{OpenEdition}

Journals

Édition électronique

URL : http://journals.openedition.org/assr/24731

DOI : $10.4000 /$ assr.24731

ISSN : $1777-5825$

Éditeur

Éditions de l'EHESS

Édition imprimée

Date de publication : 30 décembre 2012

Pagination : 282

ISSN : 0335-5985

Référence électronique

Édith Parlier-Renault, «Charlotte Schmid, Le Don de voir. Premières représentations krishnaïtes de la région de Mathurā », Archives de sciences sociales des religions [En ligne], 160 | octobre-décembre 2012, mis en ligne le 08 avril 2013, consulté le 21 septembre 2020. URL : http://journals.openedition.org/ assr/24731 ; DOI : https://doi.org/10.4000/assr.24731

Ce document a été généré automatiquement le 21 septembre 2020.

(c) Archives de sciences sociales des religions 
Charlotte Schmid, Le Don de voir. Premières représentations krishnaiites de la région de Mathurā

Paris, Publications de l'École Française d'Extrême-Orient, 2010, 749 p.

Édith Parlier-Renault

\section{RÉFÉRENCE}

Charlotte Schmid, Le Don de voir. Premières représentations krishnaïtes de la région de Mathurā, Paris, Publications de l'École Française d'Extrême-Orient, 2010, 749 p. 
1 Comment se constitue une divinité?

Comment s'affirme-t-elle face aux traditions antérieures, comment se prépare son évolution? Telles sont quelques-unes des questions abordées dans l'ouvrage de Charlotte Schmid qui porte sur les origines et les liens réciproques du culte de Kṛ̣ṇa et de Viṣnu dans la région de Mathurā et confronte les témoignages archéologiques avec les données épigraphiques et les textes épiques, principalement le Mahābhārata et le Harivamśa, premier texte consacré à la geste krṣnaïte. Charlotte Schmid commence par s'interroger sur la relation qui unit Kṛṣna à Mathurā: bien attesté aujourd'hui et depuis le $\mathrm{XV}^{\mathrm{e}}$ siècle, ce lien pourrait remonter aux premiers siècles de notre ère, époque où furent réalisées, dans un des centres artistiques majeurs de

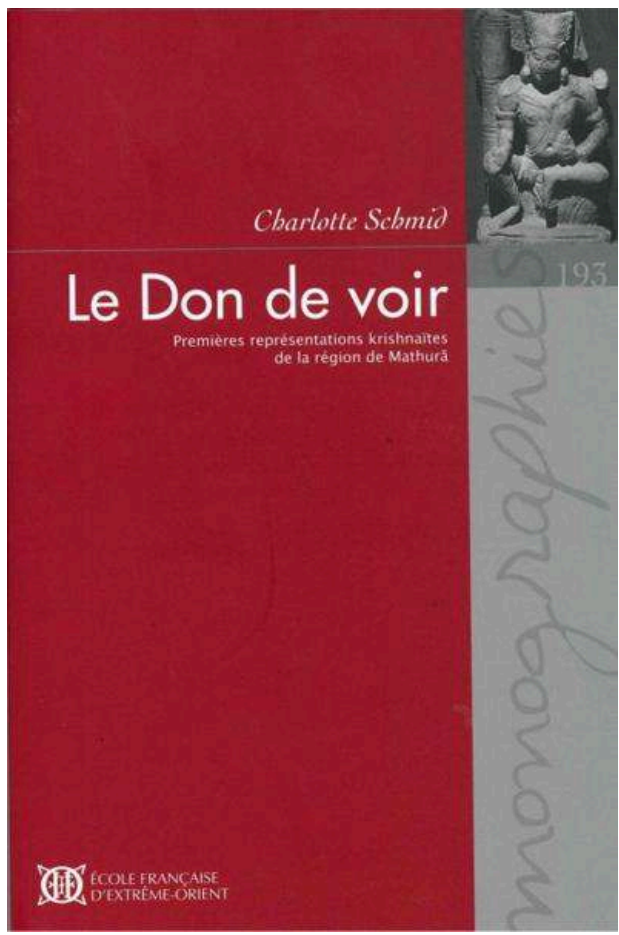
l'empire kuṣāna, les petites effigies à quatre bras que plusieurs auteurs ont identifiées comme représentant le héros du clan Vrșnịi Vāsudeva, alors qu'on les avait jusque-là considérées comme des images du dieu Viṣnu, déjà célébré beaucoup plus tôt dans le Veda, à cause de la similitude qu'elles offrent avec les représentations du dieu réalisées à partir de l'époque gupta (IV siècle).

2 S'inscrivant dans la lignée de ces recherches sur la figure de Vāsudeva, entreprises essentiellement à partir des années 1980, le livre de Charlotte Schmid met en perspective ces figures avec celles - rares, mais significatives - qui les ont précédées, celles qui les accompagnent à la même période, et surtout celles qui les ont suivies et qui voient le jour sous les Gupta, projetant ainsi un éclairage nouveau et très révélateur non seulement sur les débuts de l'iconographie de Kṛ̣ṇa et de Viṣnuu, mais sur l'émergence et l'évolution de leur culte, ainsi que sur leur relation réciproque. Elle montre que les découvertes archéologiques suggèrent en effet un processus quasiment inverse de celui que dessinent les textes, où le dieu suprême, Viṣnu, préexiste à ses manifestations - les avatāra que la littérature religieuse indienne a systématisés et où elle range habituellement Kṛṣna. C'est en fait ce dernier qui aurait fourni « la structure conceptuelle même de cette divinité qui se manifeste sous différentes formes ». Pour l'auteur, si l'on se fonde sur les témoignages archéologiques, c'est d'abord dans son culte, sa mythologie, son iconographie que s'est définie progressivement la notion même d'avatāra, "descente » de la divinité sur terre, forme et manifestation du dieu qui s'incarne dans ce monde. La notion se profile ainsi dans le rapport étroit qu'il entretient avec son frère aîné Balarāma, rapport dont les témoignages les plus anciens, en particulier les inscriptions et les images, semblent bien faire un élément clé du culte krṣnaiite à ses débuts. Les premières images connues, celles qui ornent les monnaies d'Agathocle retrouvées à Aï Khanoum, mettent en exergue la solidarité des deux frères et soulignent leur caractère guerrier. Tout aussi isolée, la divinité de Malhar réalisée sans doute aux environs de notre ère serait la première adaptation connue du modèle 
du yakșa à la représentation d'un dieu, en l'occurrence Vāsudeva, pourvu pour la première fois ici des quatre bras qui caractériseront par la suite une si grande partie des effigies brahmaniques, et dont on peut se demander en effet, comme le suggère avec finesse Charlotte Schmid, s'ils n'ont pas d'abord répondu au désir d'exprimer la symbiose des deux frères.

3 Le thème du dédoublement divin s'illustre aussi dans la représentation même de Balarāma, calquée sur celle des dieux-serpents (nāga), qui combine la forme animale et la forme humaine. Le nāga aurait ainsi fourni une sorte de modèle originel pour la représentation d'un dieu à plusieurs formes, modèle dont on retrouve l'écho dans les images de Viṣnu couché sur le serpent qui apparaîtront à partir de l'époque gupta. La relation aux nāga prend une forme plus conflictuelle dans le mythe qui raconte la soumission du serpent Kāliya, éclairant ainsi indirectement l'ambivalence du rapport qu'entretient le kṛṣnaïsme avec les cultes locaux qui précèdent l'essor du brahmanisme, dédiés aux dieux-serpents (nāga) et aux génies de la nature (yakșa).

4 L'idée d'un dieu qui se multiplie et revêt plusieurs corps est également en germe dans le concept de la famille, tel que l'illustrent ces triades de héros Viṣnu, où les deux frères encadrent une petite figure féminine qui pourrait incarner la maternité. L'auteur analyse et rapproche ces images réalisées à l'époque des Kuṣāna de celles qui relèvent de l'iconographie de Skanda, soulignant qu'elles révèlent la nécessité de faire une place à la figure féminine, sœur, épouse, mais d'abord peut-être mère, qui renverrait au phénomène de la naissance, une des sources possibles du concept d'avatāra.

5 La relation entre le dieu et son avatāra est enfin préfigurée dans le lien qui unit les deux principales formes iconographiques de Vāsudeva attestées à l'époque Kusāṇa : tandis que la figure à quatre bras paraît renvoyer au personnage du Mahābhārata, dont les traits se confondent quasiment avec ceux d'un dieu, le lutteur à deux bras qui affronte le démon-cheval Keśin renvoie au héros très humain du Harivamśá, dont la biographie vient compléter le Mahābhärata pour l'adapter aux modifications religieuses apparues au tournant de notre ère.

6 Entre le Vāsudeva des débuts de l'iconographie indienne et le Viṣnu qui s'impose à partir du IV siècle, ce sont les images « cosmogoniques » qui assurent la transition. Peu nombreuses et très spécifiques, parfois difficiles à élucider, elles illustrent les pouvoirs créateurs du dieu, soit par la multiplication des têtes ou des corps, soit par leurs aspects thériomorphiques.

7 Un tournant majeur s'amorce en effet à la période gupta, lorsque l'idéologie royale s'affirme tout en s'enracinant dans le culte brahmanique : les représentations de Viṣnu qui s'élaborent alors pour la première fois reprennent à leur compte l'iconographie des Vāsudeva à quatre bras constitués plus tôt, tandis que se développent aussi de nouvelles formes d'avatāra, qui trouvent leur modèle dans la figure antérieure du lutteur à deux bras. L'annexion par Viṣnu des caractéristiques krṣṇaïtes telle qu'elle s'était fixée sous les Kuṣanạa entraîne alors des modifications profondes dans la représentation de Kṛṣna : celui-ci se voit désormais attribuer les traits codifiés de l'enfance, en conformité avec le récit du Harivamśáa qui met l'accent sur cet aspect du héros. Un phénomène voisin s'observe aussi en contexte krṣnaïte à travers Skanda. L'apparition de ces enfants divins traduit l'importance accordée à la continuité de la lignée royale et à l'analogie entre le roi et le dieu : leur rapport à Viṣṇu ou à Śiva renvoie maintenant avant tout à celui du prince héritier au roi, du fils au père; c'est sur ce lien que repose la stabilité de la dynastie. Généalogie et avatāra sont deux de la 
descente du dieu dans le monde. L'image de Kṛșna portant le mont Govardhana est particulièrement riche d'implications multiples: elle illustre les rapports de cette figure avec le védisme, comme avec le culte des nāga et des yakșa. Son triomphe fait écho à celui du Viṣnu des Véda tout en marquant aussi sa victoire sur le dieu védique Indra. Identifié à la montagne qu'il porte, le personnage s'incorpore également les traits de ces anciennes divinités du sol, yakșa ou nāga, dont il est en quelque sorte l'émule. Conciliant valeurs brahmaniques et croyances locales, il apparaît enfin comme la figure même du roi qui " porte la terre ", selon l'expression consacrée par les textes sanscrits.

8 Ce livre qui associe une approche historique rigoureuse et la richesse des interprétations nous restitue le développement des mythes et des images dans toute sa complexité. Si la plupart des documents archéologiques pris en compte étaient déjà connus, Charlotte Schmid en renouvelle l'approche et ouvre des pistes de recherche particulièrement stimulantes. Foisonnant d'idées et de rapprochements inédits, cet ouvrage a le grand mérite de susciter toujours la réflexion et l'interrogation devant les métamorphoses de la divinité. 